\title{
Privacidade exposta
}

\section{Regina Zilberman}

Resumo Examinam-se tragédias de Eurípedes e epístolas de Ovídio, para verificar a fabricação da privacidade na correspondência representada na ficção. Contrapõem-se os textos clássicos ao diálogo epistolar trocado entre Capistrano de Abreu e Machado de Assis a propósito da natureza romanesca de Memórias póstumas de Brás Cubas. Palavras-chave privacidade; ficção; leitura; carta.

Abstract Tragedies of Euripides and letters of Ovide are analysed to understand the fabrication of privacy in the correspondence portrayed in fiction. Those classic texts are opposed to the dialogue between Capistrano de Abreu and Machado de Assis about the nature of novel in Memórias póstumas de Brás Cubas. Keywords privacy; fictions; reading; letter. 
1. Fedra, personagem de Hipólito, a tragédia que Eurípedes ( 485 a.C. - 406 a.C.) encenou provavelmente em 428 a.C., despede-se da vida, deixando uma carta ao marido ausente, Teseu. Madrasta do protagonista da peça, Fedra apaixonara-se pelo jovem, a quem confessara seu amor; desprezada, ela decide matar-se, mas não age de modo impensado: acusa Hipólito de tê-la assediado com propósitos indecorosos, razão de seu suicídio. Com esse gesto, acredita preservar sua honra e a dos filhos; e não menos importante, vinga-se do moço que a recusara de modo ultrajante.

O andamento da intriga de Hipólito depende de suas formas de comunicação; a primeira é de natureza oral: Fedra confessa à sua criada que se apaixonou pelo enteado, e a acompanhante concorda em sondar o rapaz, para testar as reações desse ao sentimento da madrasta. Na cena seguinte, Fedra ouve (mas não os espectadores) a serva, que conversa com Hipólito; esse, indignado, aparece em cena, e todos, incluindo Fedra (agora, é ela que se esconde dos interlocutores) e a doméstica, escutamos os insultos que lança contra as mulheres. Construída por meio de diálogos, as duas cenas revelam a paixão, e suas consequências, de Fedra por Hipólito, mas em nenhum momento os dois atores estão frente a frente, e sim intermediados pela aia. A comunicação depende da palavra dita, mas permanece indireta.

A outra forma de comunicação deriva do uso da escrita, valendo-se da carta, formato que preserva a possibilidade do diálogo. Teseu retorna a Trezena e encontra a esposa sendo velada pelo coro e a onipresente aia. É após lamentar a perda em versos fúnebres que se depara com uma tabuinha ainda presa às mãos da defunta. Tomado de surpresa pelo achado, o rei comenta, protelando a leitura do texto:

\section{Teseu}

Oh! Que quer dizer esta tabuinha, da sua mão querida suspensa? Quererá ela algo de novo significar?

Ou ter-me-á, a infeliz, escrito uma missiva com uma súplica sobre o nosso casamento e os nossos filhos?

Tranquiliza-te, infortunada, no tálamo de Teseu e em sua casa, nenhuma mulher entrará. 
Até esta marca, aqui deixada pelo sinete de ouro lavrado daquela que já não existe, é para mim uma carícia.

Vamos, desatemos o fio dos selos para ver o que quer dizer esta tabuinha. ${ }^{1}$

Só depois de o coro manifestar seus temores é que Teseu reage:

Grita, grita horrores

esta carta.

Para onde fugir

ao peso de meus males?

Pereci, estou perdido,

tal é, tal é a melopeia

que eu vi

por meio destas linhas soando,

infeliz!

\section{Coro}

Ai! Começo de desgraças é o que a tua linguagem anuncia. ${ }^{2}$

Na réplica, Teseu revela o conteúdo da carta, conforme a qual Hipólito teria profanado o leito paterno. ${ }^{3}$ Reage com violência e rancor, expulsando o filho e desejando sua morte, com a ajuda do deus dos oceanos, Poséidon, que, obrigado a cumprir os votos expressos por Teseu, provoca o acidente fatal que dá fim a Hipólito.

É inegável o poder da carta de Fedra, que registra sua voz para além da morte.

No âmbito da trama dramática, por sua vez, a carta de Fedra colabora para o andamento da intriga: Eurípedes tinha necessidade de introduzir um meio que permitisse a uma personagem, já falecida naquele ponto da ação, transmitir uma mensagem capaz de desencadear a mudança da fortuna, tão importante para o

\footnotetext{
1 EURIPEDES. Hipólito. Introdução, versão do grego e notas de Bernardina de Sousa Oliveira. Coimbra: Instituto Nacional de Investigaçāo Científica; Centro de Estudos Clássicos e Humanísticos da Universidade de Coimbra, 1979, p. 65.

2 Ibidem, p. 66

3 Ibidem, p. 67.
} 
transcurso da tragédia. ${ }^{4}$ Homem do Iluminismo ateniense do século $\mathrm{v}$ a.C., representado pelos sofistas, Eurípedes não colocaria em cena fantasmas, espíritos ou demônios, como, muitos séculos depois, fazem os elizabetanos William Shakespeare (1564-1616) e Christopher Marlowe (1564-1693). Ele usa um recurso de seu tempo - a escrita - provavelmente em fase de expansão entre os membros da camada dominante.

E importante notar que, para que o recurso dramático fosse verossímil, ele precisava ser conhecido e aceito pelo público; assim, pode-se presumir que fosse digna de crédito a cena em que Teseu lê a carta de Fedra, cena que supõe uma situação anterior - a de Fedra redigindo o documento que o marido encontra nas mãos da esposa morta. Mulheres habilitadas à escrita e à leitura não deviam ser muitas na Grécia do século v a.C.; contudo, Fedra não surpreende seu público, até porque, antes de se suicidar, avisa a criada e o coro - e, por extensão, os espectadores - de que não venderá barato sua própria morte, provocando, com ela, a desgraça de Hipólito.

A tabuinha, em que Fedra consigna suas palavras, constituía suporte tradicional de registro da escrita, usada desde o quarto milênio a.C. pelos sumérios, povo a quem se atribui a invenção do alfabeto cuneiforme. À época em que Hipólito foi representado, o papiro, oriundo do Egito, o principal produtor desse material, era já bastante utilizado, tendo sido introduzido na Grécia por volta de 650 a.C. ${ }^{5}$ Como a tragédia se passa nos tempos da mitologia, e não na época de Eurípedes, pode-se cogitar que o autor quisesse acentuar a verossimilhança da obra, fazendo Fedra registrar suas palavras na matéria-prima de que então disporia, as primitivas e trabalhosas tabuletas, que requeriam o emprego de um estilete triangular específico para escrever e, provavelmente, muita habilidade motora, além do necessário letramento.

Hipólito não constitui a única tragédia em que Eurípedes se vale do recurso das cartas para acelerar a intriga. Também em Ifigênia em Aulide a troca de correspondência é matéria da ação, apresentando-se como assunto desde o prólogo:

\section{Cf. ARISTOTELES. Poética. Porto Alegre: Globo, 1966.}

5 Cf. a respeito da história da escrita e de seus suportes na Antiguidade: BÁEZ, Fernando. História universal da destruição dos livros. Das tábuas da Suméria à guerra do Iraque. Trad. de Léo Schlafman. Rio de Janeiro: Ediouro, 2006; FISCHER, Steven Roger. História da leitura. Trad. de Cláudia Freire. São Paulo: Editora UNESP. 2006; JEAN, Georges. A escrita - memória dos homens. Trad. de Lídia da Mota Amaral. Rio de Janeiro: Objetiva, 2002; MARTIN, Henri-Jean. Histoire et pouvoirs de léerit. Paris: Albin Michel, 1996. 
Agamemnon, dialogando com um ancião, explica-lhe que enviara carta a Clitemnestra, pedindo-lhe que permitisse a viagem da filha, Ifigênia, ao acampamento grego, a fim de celebrar o casamento da moça com Aquiles.

Tal como Fedra, Agamemnon mentira, pois o objetivo para a vinda de Ifigênia era oferecê-la em sacrifício a Ártemis, para, conquistando as benesses da deusa, ter condições favoráveis de zarpar na direção de Troia, onde resgataria Helena, sua cunhada, então no poder de Páris. Arrependido, Agamemnon desmente-se em nova missiva, em que pede que a moça permaneça em Micenas, escapando à morte que a espera no porto de Áulide, onde se encontra o exército aqueu. É essa segunda carta que ele entrega ao ancião, registrada nas tabuletas lacradas por ele. $\mathbf{O}$ diálogo entre os dois homens tem como objetivo esclarecer o significado da ação do general aqueu. Mas o ancião justifica por que Agamemnon precisa verbalizar o conteúdo da missiva; se souber do que trata o documento, poderá reproduzi-lo verbalmente; após ser lido por sua destinatária, sua "língua o confirmará". Mais adiante na mesma cena, a questão se inverte: o ancião não tem certeza se a filha e a esposa de Agamemnon acreditarão em suas palavras; o interlocutor garante que sim, desde que ele "guarde o selo que cobre essa carta"?

Também nesse caso, Eurípedes parece utilizar um procedimento comum à época em que a ação se passa. Steven Roger Fischer destaca que, no Egito do segundo milênio antes de Cristo, a correspondência "não tratava da leitura como a conhecemos hoje, mas era o testemunho oficial de um meio oral". ${ }^{8}$ A transmissão não se limita ao suporte físico, mas precisa ser reiterada verbalmente por seu portador: “a mensagem 'verdadeira' não está na tabuleta cuneiforme ou na carta em papiro, mas na transmissão oral final: ou seja, ela reside no escriba que lê a mensagem em voz alta para o destinatário."9

Contudo, a carta de Agamemnon não chega a seu destino, pois seu irmão, Menelau, encontrando o ancião, arranca-a das mãos do outro. Agamemnon ouve o tumulto causado pela intervenção de Menelau e acode seu servo; mas o irmão ameaça

6 EURÍPEDES. Ifigenia en Aulide. In: Obras dramáticas. Buenos Aires: El Ateneo, 1951, p. 422.

7 Ibidem, p. 423.

8 FISCHER, Steven Roger. Op. cit., p. 26.

9 Ibidem, p. 27. 
revelar o teor do documento aos demais, soldados e generais gregos que aguardam a ordem de partir para conquistar Troia. Agamemnon fica indignado com a atitude desrespeitosa de Menelau, que rompera o selo da carta; porém, a discussão é interrompida ao ser anunciada a chegada de Ifigênia e Clitemnestra a Áulide, evidenciando que, mesmo que o ancião tivesse completado a tarefa, não teria tido tempo para evitar a catástrofe, consumada algumas cenas mais adiante. Em Hipólito, a mensagem escrita por Fedra ajudou a precipitar os acontecimentos, função preenchida, em Ifigênia em Áulide, pela primeira carta remetida por Agamemnon, que a menciona, enquanto escreve a segunda. É esse segundo documento que, verbalizado, explica a situação em que se encontram as personagens, recapitulando os eventos já transcorridos e expondo os conflitos internos de Agamemnon, bem como a complexidade de sua posição de, ao mesmo tempo, líder do exército aqueu e pai da moça a ser imolada no altar dedicado à deusa Ártemis. O valor da segunda carta não reside, pois, no que está escrito, mas no que é exposto oralmente pelo general aqueu ao ancião. Contudo, Eurípedes não deixou de reproduzir o ritual relativo à produção e remessa de correspondência, processo que supõe tanto a etapa de redação do documento, dependendo da presença do suporte - a saber, as tabuletas de argila, similares àquelas empregadas por Fedra -, quanto $o$ fechamento por meio do selo, a escolha do portador confiável e a transmissão oral do conteúdo do texto escrito, para a eventualidade de esse não poder ser lido.

A alusão às tabuletas pode decorrer do desejo de conferir maior verossimilhança aos acontecimentos, situados no tempo mítico. Talvez elas provoquem maior dramaticidade à ação colocada em cena. Outra hipótese é a de que, embora disseminado, o papiro ainda não tinha substituído amplamente as tabuinhas de barro. De um modo ou de outro, a situação representada não deveria surpreender o público, indicando que os atos de enviar correspondência a pessoas distanciadas no espaço ou de deixar algum tipo de recado por escrito já ocupavam o imaginário dos cidadãos de Atenas e podiam ser matéria de ficcionalização por meio da arte dramática. A correspondência, que dispunha de uma tradição pública enquanto documento entre homens ligados ao Estado, aparece, em Eurípedes, na condição de comunicação privada, mantida entre maridos e esposas, para falar de filhos ou enteados.

Por outro lado, nos dramas de Eurípedes, as cartas são escritas e lidas, mas tomamos conhecimento delas por meio da transmissão oral por parte de remetentes 
(Agamemnon, em Ifigênia em Áulide) ou destinatários (Teseu, em Fedra). Os gregos não transformaram a arte da correspondência num gênero literário, ao contrário dos romanos, para quem a epístola converteu-se numa de suas principais fontes de expressão e um gênero in its own right.

A literatura latina contou desde o século i a.C. com prestigiados autores de cartas, sendo o tribuno Cícero (106 - 43 a.C.) um de seus principais usuários, já que a ele se atribui a redação de mais de novecentas missivas, públicas ou privadas. As Epistulae ad familiares (Epistolas aos familiares, escritas entre 62 e 43 a.C.) e as Epistulae ad Quintum fratrem (Epistolas ao irmão Quinto, escritas entre 60 e 54 a.C.) referemse à correspondência trocada com parentes, atividade que manteve até a morte.

Mais jovem que Cícero, Horácio (65 a.C. - 8 d.C.) também utilizou a epístola como forma de comunicação, conferindo-lhe status literário, sobretudo porque, embora dirigidas a um destinatário específico, estavam destinadas à leitura de um público mais amplo e anônimo. Exemplar de seu procedimento é a Epistula ad Pisones [Epistola aos Pisões], provavelmente de 14 a.C. e endereçada ao cônsul romano Lúcio Pisão e seus filhos, designada posteriormente, por Quintiliano (35 d.C. -96 d.C.), como Arte poética, já que o autor procura estabelecer padrões válidos e universais para a criação verbal.

A ficcionalização da epístola teve, contudo, que aguardar Ovídio (43 a.C. - 17 d.C.), que compôs, nas primeiras décadas do século i d.C. e já no exílio para onde o enviara o imperador Augusto (63 a.C. - 14 d.C.), as Epistulae Heroidum, as Cartas das heroinas ou Heroidas. O conjunto contém 21 cartas, sendo dezoito delas atribuídas a mulheres que, dirigindo-se a seus amados, expressam seus sentimentos. A maioria das remetentes provém da mitologia grega, como Penélope, que escreve a Ulisses, ou Helena, que se dirige a Páris. Mas Ovídio inclui uma carta da poeta Safo (século vir a.C.) a Faon, assim como uma missiva ao troiano Enéas, enviada pela cartaginesa Dido, personagem popularizada na Eneida, que Virgílio (70 a.C. - 19 a.C.) concluíra em 19 a.C. Não é a única obra de Ovídio pertencente ao gênero epistolar: nos quatro livros das Epistulae ex Ponto [Cartas pônticas], igualmente redigidas no desterro, endereça cartas a políticos romanos, pedindo-lhes que intercedam por ele e obtenham a licença para retornar a Roma; em Tristia [Tristes], o mesmo propósito reaparece, embora Ovídio omita o nome dos destinatários, supostamente para não comprometê-los. 
O surpreendente das Heroidas não é o uso da epístola como forma de comunicação, pois, conforme sugere a tradição romana, o gênero enraizara-se na cultura latina, tendo sido cultivado por oradores e homens de Letras. Ovídio, porém, retoma o fio legado por Eurípedes, ao ficcionalizar a redação da correspondência, que, desse modo, se transfere da esfera do real para a da fantasia. Por sua vez, as cartas das heroínas lendárias são escritas para serem lidas, e não reproduzidas oralmente; portanto, introduzem a privacidade enquanto condição de recepção do texto, acentuando um traço que, na continuidade histórica, caracterizará o gênero, independentemente de ser o texto fictício ou verdadeiro. Por último, Ovídio desenvolve um elemento que estava contido no Hipólito, de Eurípedes, mas não suficientemente desenvolvido - a voz feminina, como expressão verbal do universo da mulher.

Não espanta que, na coleção de Ovídio, Fedra reapareça, agora na posição de autora de uma carta dirigida a Hipólito, e não a Teseu, como fizera Eurípedes, em sua tragédia. Essa, por sua vez, ocupa o pano de fundo do texto de Fedra, constituindo a principal referência literária do escritor latino.

Fedra abre a epístola, saudando Hipólito e solicitando que ele não abandone o texto, acompanhando-o até as últimas linhas: "Lê até o final tudo o que está aqui." Argumenta que a leitura não pode fazer mal a ele, pois "mesmo inimigos leem cartas escritas por seus inimigos". Reconhece, por outro lado, que recorreu a esse expediente, por não conseguir falar com o rapaz: "Três vezes tentei falar-te, três vezes minha língua, inútil, ficou pregada, três vezes o som morreu sobre o solo de minha boca"."

Contudo, não assume o ato sozinha, alegando que é comandada pelo amor, que "reina sobre os próprios deuses". Se assim é, ela não poderia agir de modo diferente, circunstância que atenua sua culpa. Tal como na tragédia de Eurípedes, Fedra está possuída pelos poderes de Vênus, que a induz à confissão da paixão pelo enteado. Na epístola que Ovídio lhe atribui, porém, Fedra incorpora o sentimento amoroso de modo radical, revelando ao rapaz, e não à criada, isto é, a outra

10 OVIDE. Les Héroïdes. Trad. de Émile Ripert. Paris: Garnier, [1930?] p. 57-65. A tradução levou em conta a edição francesa, comparada à tradução para o inglês, por James $M$. Hunter, encontrável no endereço http://www. tkline.freeserve.co.uk/Heroides1-7.htm\#_Toc523806688, acessado em $1^{\circ}$ de janeiro de 2007. 
mulher, sua intimidade: "queimo por dentro; queimo, e meu coração esconde um ferimento secreto". É a expressão do desejo que marca o discurso de Fedra:

Sou arrastada a artes incomuns: um desejo me dirige para as bestas selvagens. Agora a primeira das deusas é para mim Diana, conhecida por seu arco curvo; seguindo-a, acompanho tua preferência. Agrada-me andar pelas florestas, apanhar os cervos em armadilhas, impelir os cães velozes ao cume das montanhas, lançar com meus braços o dardo vibrante, jogar meu corpo sobre as ervas da terra.

A fala do desejo permite materializar a figura de Hipólito, cujo aspecto físico seduz Fedra: "tu me agradaste: o amor penetrou até o fundo de meus ossos; tua túnica era branca, teus cabelos estavam cingidos de flores; um casto rubor coloria tua face dourada; este rosto que as outras mulheres declaravam rude e austero, para Fedra não era rude, era másculo". A virilidade de Hipólito, por sua vez, precisa manifestarse igualmente nas artes do amor. Perguntando ao rapaz "por que praticar as artes de Diana de túnica flutuante e evitar o que devemos a Vênus?", ela mesma responde, afirmando ser necessário "estender um arco", para ele não "perder elasticidade".

$\mathbf{O}$ argumento de Fedra, referindo-se negativamente à castidade de Hipólito - informação igualmente importada da tragédia de Eurípedes -, é o ponto de partida para a introdução da temática erótica e, sobretudo, para que Fedra rejeite a falsa moralidade que separa o casal. Lembra primeiramente que Teseu os enganou a ambos, não sendo, pois, merecedor da fidelidade da esposa e da lealdade do filho. Acusa o marido de ter deixado seu reino, Trezena, para ajudar Pirito, o companheiro de lutas contra os centauros; acusa-o igualmente de ter exterminado a família dela, pois, "com uma clava de três nós, quebrou os ossos de meu irmão [o Minotauro] e dispersou-os no solo; abandonou minha irmã [Ariadne], deixando-a presa das bestas ferozes"; e acredita poder contar com a cumplicidade de Hipólito, pois Teseu ocasionou a morte da mãe do rapaz [a amazona Hipólita]: "A mais corajosa das mulheres que portam o machado te criou, com vigilância digna de mãe; se procurares onde ela está, Teseu varou-lhe o corpo com sua espada, prova de que não salvaste tua mãe". Além disso, Teseu não reconheceu Hipólito como filho legítimo e, na condição de bastardo, o moço não pode herdar Trezena, o reino administrado por seu pai. 
Só depois de desqualificar Teseu, Fedra recorre a seu principal argumento: as relações que mantiverem serão legítimas, pois seguirão o paradigma de Júpiter, amante da própria irmã. Fedra rejeita a "velha moralidade" e cita exemplo recente:

E se me veem, madrasta, unida a meu enteado, que esses nomes vãos não assustem teu espírito! Esta velha moralidade, que as próximas eras deverão abolir, existia quando Saturno dirigia seu reino primitivo. Júpiter legitimou tudo o que o agradava, e a lei divina autorizou qualquer irmã a desposar o irmão. A aliança forma uma cadeia sólida de parentesco, quando a própria Vênus impõe seus laços.

Na sequência, reforça a mesma ideia, alegando que as demonstrações de afeto entre a madrasta e o enteado serão percebidas como manifestações de afeto familiar:

Não há nenhum problema; pode-se esconder tudo; o parentesco nos servirá de desculpa; a falta poderá se cobrir de seu nome. Seremos elogiados, quando formos vistos abraçados; dir-se-á que sou uma madrasta boa para meu enteado. Não precisarás abrir no escuro a porta de um marido temível, não terás de enganar um guarda. Uma mesma casa abrigou a nós dois, uma mesma casa nos abrigará; tu me beijaste em público, tu me beijarás em público. Estarás em segurança comigo e tua falta será elogiada, mesmo quando fores visto em meu leito. Não tardes mais e apressa-te em assinar este tratado; o amor que é cruel para mim, que ele seja doce assim para ti.

Fedra, contudo, está ciente de que sua proposta agride o decoro, mas defende-se, afirmando que, na posição de mulher apaixonada, abriu mão da decência e da vergonha: "os amantes perdem toda decência. Perdi meu pudor, meu pudor em fuga enfraqueceu meus estandartes". Conclui a epístola, implorando a atenção de Hipólito; e arremata com uma frase que expressa sua extrema fragilidade: "Estas preces, rego-as com minhas lágrimas: as preces, tu as lês, mas as lágrimas, imagina-as!"

Ao compor a carta, Ovídio revela a atenção conferida à obra original de Eurípedes: Hipólito ignora a madrasta, por estar voltado ao culto a Diana e aos jogos da caça; ela, por sua vez, intoxicada por Vênus, está apaixonada e desconhece limites. Teseu, da sua parte, distanciou-se do lar, dedicado às atividades guerreiras que $o$ chamam. Se, na obra de Eurípedes, Ártemis e Afrodite se digladiam pelo poder 
sobre o rapaz avesso ao amor, na missiva de Fedra, é a remetente quem internaliza o poder de Eros, obrando para comover o indiferente caçador.

A internalização do discurso vem acompanhada da manifestação do desejo, exposto na fala de Fedra, que dá conta de seu descontrole emocional e erótico. Esse é irracional e inconsciente, mas não incide em privação de valores morais. Essa perda vai aparecer em outro momento do texto, quando a madrasta apela aos exemplos dos deuses para justificar a validade de seu ato: o incesto é legítimo, porque Júpiter o pratica, além de moderno, pois substituiu a norma de Saturno, pai do atual senhor do Olimpo, por outra, mais nova e mais pragmática.

No discurso de Fedra, cruzam-se o horizonte moral e o apelo erótico, indicando que eles não podem ser conciliados. Induz Hipólito à transgressão e reforça a motivação amoral, alegando que seus atos espúrios não seriam reconhecidos. $\AA$ transgressão, ela soma a simulação, caracterizando a perspectiva feminina com que Ovídio expõe o sugerido incesto.

É quando descortina ao leitor o erotismo desde a perspectiva da mulher e a transgressão dissimulada que Ovídio revela conhecer a ótica feminina. Pode empregar a primeira pessoa no feminino, sem parecer artificial; e adentrar-se na intimidade de sua personagem sem perder de vista o foco interior. Seu texto prima pelo tom confessional, que somente pode ser expresso, se se aceitar que a carta é documento privado, confidencial, sigiloso. É nesse sentido que, empregando um gênero que encontrou sua principal expressão literária entre os romanos, Ovídio conferelhe as características que passam a ser consideradas propriedades específicas dele - sua singularidade.

Contudo, Ovídio alcançou esse resultado, porque recorreu à ficção. Valeu-se de uma personagem pertencente à mitologia, cujas marcas principais foram desenvolvidas por Eurípedes. E inventou para ela sentimentos e reações, configurando um padrão a que, na sequência histórica, recorreram, poucos anos depois, o conterrâneo Sêneca ( 4 d.C. -65 d.C.) e, muitos séculos mais tarde, o francês Jean Racine (1639 - 1699).

A alteração no comportamento de Fedra e de seu modo de expressão relaciona-se, por sua vez, às transformações ocorridas nos suportes da escrita e nas formas de comunicação. A Fedra do Hipólito dependeu de seu texto fixar-se em tabuletas de argila, cuja leitura tornou-se pública, porque enunciado o texto por Teseu por 
ocasião do funeral da suicida. A Fedra de Ovídio possivelmente se valeu do papiro ou, de maneira mais conveniente, do pergaminho, material em uso na Europa mediterrânea desde o século II a.C." Observe-se que, na abertura do documento, Fedra solicita a Hipólito que leia seu texto até o final; quando se despede, lembra que o enteado lê suas preces, mas não vê as lágrimas da remetente, restando-lhe a alternativa de imaginá-las - cenas, as duas, improváveis se o rapaz tivesse nas mãos tabuletas similares àquelas enviadas a Teseu, nos versos de Eurípedes.

Tal como na tragédia de Eurípedes, Ovídio supõe uma mulher letrada e bem informada que pode invocar exemplos da mitologia para se comunicar com o amado; mas, ao contrário do que ocorria na obra anterior, ele pode contar com um leitor que decifra o texto solitariamente, documento que pode chegar a ele de modo, supõe-se, sigiloso, porque o suporte onde é registrado tem natureza mais portátil e é mais facilmente manipulável. Sua privacidade fica, assim, resguardada, não apenas porque o tema apresenta caráter íntimo e transgressivo, mas também porque pode circular de maneira discreta e quase clandestina.

Numa época em que a leitura silenciosa era raramente praticada, ${ }^{12}$ pois começa a se difundir somente depois do século III a.C., ${ }^{13}$ Ovídio supõe um instrumento da leitura solitária e individual. Essa poderia supor a expressão oral, em voz alta;

11 Cf. a respeito MARTIN, Henri-Jean. Op. cit. BATTLES, Matthew. A conturbada história das bibliotecas. Trad. de João Vergilio Gallerani Cuter. São Paulo: Planeta, 2003.

12 Jesper Svenbro observa a propósito da leitura silenciosa entre os gregos na Antiguidade, que provavelmente modulou o modo de ler entre os latinos: "a leitura silenciosa dos gregos permanece [...] determinada pela leitura em voz alta, da qual ela conserva como que um eco interior irreprimível". (SVENBRO, Jesper. A Grécia arcaica e clássica: a invenção da leitura silenciosa. In: CAVALLO, Guglielmo; CHARTIER, Roger (Org.). História da leitura no mundo ocidental. Trad. de Fulvia M. L. Moretto, Guacira Marcondes Machado e José Antônio de Macedo Soares. São Paulo: Ática, 1998, p. 67). Ele também escreve que, "para os gregos, ler significava ler alto. Não que fossem incapazes de ler silenciosamente, [...] mas o modo normal de ler um texto na Grécia antiga era, sem dúvida, lê-lo em voz alta." (SVENBRO, Jesper. Phrasikleia. An Anthropology of Reading in Ancient Greece. Ithaca and London: Cornell University Press, 1993, p. 18. Grifo do A.).

13 A respeito da leitura silenciosa, v. BLANCK, Horst. Das Buch in der Antike. München: Beck, 1992; CHARTIER, Roger. As revoluçōes da leitura no Ocidente. In: ABREU, Márcia (Org.). Leitura, história e história da leitura. Sāo Paulo: FAPESP; Campinas: ALB; Mercado das Letras, 2000; FISCHER, Steven Roger. Op. cit.; SCHNAPP, Jeffrey T. Liçōes de leitura: Agostinho, Proba e o detournement cristāo da Antiguidade. Rio de Janeiro: Universidade Estadual do Rio de Janeiro, 1995. 
mas o discurso não poderia ser público, sob pena de expor a infração moral advogada por Fedra. Forçando a privacidade da leitura da carta, Ovídio lega ao gênero epistolar uma característica que ele passa doravante a carregar.

2. Em 10 de janeiro de 1881, Capistrano de Abreu (1853-1927), na época colaborador de A Gazeta de Notícias, do Rio de Janeiro, e funcionário da Biblioteca Nacional, escreve uma carta a Machado de Assis (1839-1908), em que acusa o recebimento de Memórias póstumas de Brás Cubas, volume lançado pouco tempo antes pela Tipografia Nacional, depois de ter sido impresso em partes pela Revista Brasileira. ${ }^{14}$ Diz o mais tarde professor do Colégio Pedro II e ilustre historiador, autor dos Capitulos de História Colonial, de 1907:

Campinas, 10 de janeiro de 1881

Dear Sir, - hoje às 7 horas da manhã, poucos momentos antes de tomar o trem de Rio Claro para Campinas, me foi entregue com a sua carta de 7 o exemplar do Brás Cubas que teve a bondade de me enviar. Li de Rio Claro a Campinas, e, preciso dizer-lhe? a impressão foi deliciosa, - e triste também, posso acrescentar. Sei que há uma intenção latente porém imanente a todos os devaneios, e não sei se conseguirei descobrila. - Em S. Paulo, por diversas vezes, eu e Valentim Magalhães nos ocupamos com o interessante e esfíngico X. Ainda há poucos dias, ele me escreveu: "O que é Brás Cubas em última análise? Romance? dissertação moral? desfastio humorístico?" - Ainda o sei menos que ele. A princípio me pareceu que tudo se resumia em um verso de $\mathrm{Ha}$ mlet de que me não lembro agora bem, mas em que figura The pale cast of thought. Lendo adiante, encontrei objeçōes... et je jette ma langue aux chiens. - Pretendo passar dois dias em Campinas, e aqui lerei o que me falta, que infelizmente não é tanto quanto desejaria. Livros como Brás Cubas é que deveriam assumir as proporções de

14 A respeito das ediçōes de Memórias póstumas de Brás Cubas no século XIX, v. HOUAISS, Antônio et alii. Introdução crítico-filológica. In: ASSIS, Machado de. Memórias póstumas de Brás Cubas. Rio de Janeiro: Instituto Nacional do Livro, 1960. V. também ZILBERMAN, Regina. Minha theoria das ediçōes humanas Memórias póstumas de Brás Cubas e a poética de Machado de Assis. In: ZILBERMAN, Regina et alii. As pedrase o arco: fontes primárias, teoria e história da literatura. Belo Horizonte: Editora da UFMG, 2004. 
Rocambole ou Três Mosqueteiros. - Só no dia 15 partirei para o Rio. Se antes quiser me dar quaisquer ordens, enderece a carta para S. Paulo - rua do Gasômetro 17, em casa de Valentim Magalhães.- Adio.

Bien à vous,

J. C. Abreu's

Nessa correspondência, Capistrano parece não ter muita certeza do que dizer a Machado, manifestando interrogações e hesitações; não por coincidência o crítico lembra um trecho do monólogo de Hamlet, em que o herói oscila entre o ser e o não ser. ${ }^{16}$ Ele confessa não saber em que gênero enquadrar a obra lida. Seus parâmetros, em matéria de romance, são os volumes de aventuras de Ponson du Terrail (1829-1871), como o Rocambole, série iniciada em 1857, e de Alexandre Dumas (1802-1870), cuja novela Os três mosqueteiros data de 1844, - aos quais o livro de Memórias póstumas se assemelha, por ter sido publicado antes em folhetim, e, ao mesmo tempo, se contrapõe, por corresponder ao que, idealmente, aqueles textos deveriam ser.

Desconhece-se a resposta de Machado, se é que o romancista escreveu de volta ao crítico. Esse, porém, deu continuidade ao diálogo, publicando no domingo de 30 de janeiro de $\mathbf{1 8 8 1}$ uma resenha sobre Memórias póstumas no jornal de que era colaborador, na seção de "Livros e Letras"." Uma pergunta abre seu texto: "As Memórias póstumas de Brás Cubas serão um romance?". A questão é solucionada logo a seguir: "Em todo o caso são mais alguma coisa. O romance aqui é simples

15 RODRIGUES, José Honório (Org.). Correspondência de Capistrano de Abreu. $2^{\text {a }}$ ed. Rio de Janeiro: Civilização Brasileira; Brasília: Instituto Nacional do Livro, 1977, p. 373-4

16 O trecho encontra-se ao final do monólogo, no seguinte contexto: "Thus conscience does make cowards of us all;/ And thus the native hue of resolution / Is sicklied o'er with the pale cast of thought,/ And enterprises of great pith and moment/ With this regard their currents turn away,/ And lose the name of action."In: SHAKESPEARE, William. Hamlet, Prince of Denmark. In: Tragedies. Londres: Dent, 1964, p. 522.

17 Cf. MACHADO, Ubiratan. Machado de Assis: roteiro da consagração. Rio de Janeiro: EDUERJ, 2003, p. 129-33. A versāo fac-similada dessa resenha encontra-se em CORDEIRO, Verbena Maria Rocha. Itinerários de leitura: o processo recepcional de Memórias póstumas de Brás Cubas. Porto Alegre: Pontifícia Universidade Católica do Rio Grande do Sul, 2003. 2 v. (mimeo). 
acidente. O que é fundamental e orgânico é a descrição dos costumes, a filos social que está implícita".

Na sequência do artigo, Capistrano resume os acontecimentos do livro de $\mathrm{Ma}$ do, buscando a "filosofia social" que, nas suas palavras, a obra expõe. Desvi pois, da questão originalmente formulada, que responde de maneira oblíqu: que não afirma, nem desmente a natureza romanesca da obra.

À época em que o livro foi publicado, a teoria do romance dava seus pris ros passos na Europa, pois Gustave Flaubert (1821-1880) lançara Madame Bor obra que desafia a natureza do gênero tal como era praticado até então, por décadas antes, em 1857. Data do mesmo ano de 1881 a edição de Portrait of a $l$ de Henry James (1843-1916), autor que somente nos primeiros anos do séc $\mathbf{x x}$ reúne seus estudos críticos em The art of the novel. Obra igualmente sem: foi A teoria do romance, de Georg Lukács (1885-1971), de 1914. Não espanta Capistrano associasse o romance ao folhetim, em voga depois de 1835 e extre mente popular à época do lançamento de Memórias póstumas, conforme suge menção a Ponson du Terrail, um de seus expoentes mais conhecidos.

A interrogação de Capistrano se justifica, pois, assim como as conexões literá que estabelece. O surpreendente é que, depois de reparti-la com o autor da o divida-a com os leitores dos "Livros e Letras", de A Gazeta de Notícias, tornal público o debate. Machado de Assis, por sua vez, não fez por menos: ao lar a quarta edição de seu romance, em 1899, introduz um prólogo, em que retc o diálogo com seu correspondente de 1881, observando no segundo parágr "Capistrano de Abreu, noticiando a publicação do livro, perguntava: 'As Memó póstumas de Brás Cubas são um romance?"'18 Só que não é Machado quem ponde a Capistrano, mas Brás Cubas, pois escreve no mesmo prólogo:

Ao primeiro respondia já o defunto Brás Cubas (como o leitor viu e verá no pı go dele que vai adiante) que sim e que não, que era romance para uns e não o para outros. ${ }^{19}$

18 ASSIS, Machado de. Memorias posthumas de Braz Cubas. $4^{2}$ ed. Rio de Janeiro/Paris: Garnier, 1899, p. VII. 19 Ibidem, p. VII-VIII. 
Com efeito, desde a primeira edição em livro, a de 1881, que Capistrano lera na viagem de trem entre Rio Claro a Campinas, Machado introduzira uma apresentação, em que o protagonista do romance, Brás Cubas, dirigia-se "Ao leitor", discutindo a forma do texto em questão. É quando classifica o livro de "obra difusa", em que adota a forma livre "de um Sterne, de um Lamb, ou de um Maistre", complementando: "a gente grave achará no livro umas aparências de puro romance, ao passo que a gente frívola não achará nele o seu romance usual".20

A questão do gênero estava, pois, posta desde o prólogo assinado por Brás Cubas, $\mathrm{e}$, ao dialogar com Machado, por meio da correspondência, Capistrano trocava ideias simultaneamente com o criador e a criatura. Ao transportar o diálogo para o jornal, o crítico deu continuidade ao trânsito entre realidade e fantasia, pois abre o texto com a retomada do ponto trazido à baila pela personagem inventada pelo ficcionista.

Quase vinte anos depois, no prólogo impresso em 1899 (provavelmente escrito para a re-edição de 1896 de Memórias póstumas, mas não editado nessa ocasião), ${ }^{21}$ Machado não rompe a ilusão ficcional, pois transfere para o herói do romance a resposta ao crítico de 1881. Ao fazê-lo, ele parece conferir historicidade à personagem; mas talvez estivesse igualmente ficcionalizando o diálogo com o já então consagrado historiador e docente do Colégio Pedro II.

Ao contrário do que ocorre na epístola em que Ovídio imagina Fedra dirigindose ao indiferente Hipólito, Capistrano e Machado tornam público um diálogo privado, já que a pergunta da carta migra para a interrogação que abre a resenha. Mas o processo inicia-se quando Capistrano confessa para Machado suas dúvidas quanto à natureza do gênero a que pertence Memórias póstumas. A confidência reaparece na resenha, observação não resolvida pelo crítico que Machado guarda na memória por longos anos, até respondê-la, outra vez valendo-se do documento público - o livro impresso. Mas não fala em seu próprio nome, recorre ao álibi da personagem, a quem cita na condição de alteridade autossuficiente.

Valendo-se desse expediente, talvez Machado tenha procurado recompor a privacidade da correspondência, pois esconde-se por trás da persona de Brás. Com

ASSIS, Machado de. Memorias posthumas de Braz Cubas. Rio de Janeiro: Tipografia Nacional, 1881, p. V-VI. A citação traz a ortografia atualizada.

21 V. a respeito HOUAISS, Antônio et alii. Op. cit. 
um único movimento, recompõe também os vínculos entre a privacidade da correspondência e a ficcionalidade do texto. Eis a segunda máscara que esconde a primeira, e graças a ela o privado pode tornar-se público, já que, tal como nas Heroidas de Ovídio, o processo acontece dentro de uma obra literária que será lida não pelo destinatário nomeado, mas pelos leitores anônimos que tiverem acesso aos livros onde os textos se materializam.

Para ser público, o texto precisa simular sua qualidade de privado, e assim alcançar o leitor, que acredita na confidência graças às sucessivas máscaras que aquela adota.

Regina Zilberman é graduada em Letras pela UFRGS, doutorou-se na Universidade de Heidelberg, Alemanha. Foi Honorary Research Fellow na London University e fez pós-doutorado na Brown University, EUA. Foi professora titular da PUCRS; é pesquisadora 1A do CNPq. Suas publicações mais recentes são: Fim do livro, fim dos leitores? [2001]; O preço da leitura: leis e números por detrás das letras [2001, em coautoria com Marisa Lajolo]; O tempo e o vento: história, invenção e metamorfose [2004, em coautoria com Maria da Glória Bordini]; Como e por que ler a literatura infantil brasileira [2005]. 